TAMKANG JOURNAL OF MATHEMATICS

Volume 33, Number 3, Autumn 2002

\title{
A SHARP BOUND FOR THE ERROR IN THE CORRECTED TRAPEZOID RULE AND APPLICATION
}

\author{
N. S. BARNETT, P. CERONE AND S. S. DRAGOMIR
}

\begin{abstract}
Sharp bound for the perturbed trapezoidal rule is obtained in this note. The sharpness is demonstrated by showing equality for a particular function.
\end{abstract}

\section{Introduction}

Atkinson [1] defined the quadrature rule

$$
P T(f ; a, b):=\frac{b-a}{2}[f(a)+f(b)]-\frac{(b-a)^{2}}{12}\left[f^{\prime}(b)-f^{\prime}(a)\right]
$$

as a corrected trapezoidal rule and obtained it using an asymptotic error estimate approach which does not provide an expression for the error bound.

The authors examine a variety of trapezoidal type results in [2] - [4]. The current note proves that

$$
\left|\int_{a}^{b} f(x) d x-P T(f ; a, b)\right| \leq C(a, b)\left[\frac{1}{b-a}\left\|f^{\prime \prime}\right\|_{2}^{2}-\left[f^{\prime} ; a, b\right]^{2}\right]^{\frac{1}{2}},
$$

where $C(a, b)=\frac{(b-a)^{3}}{12 \sqrt{5}}$ is sharp,

$$
\|h\|_{2}^{2}=\int_{a}^{b} h^{2}(t) d t<\infty
$$

and $[h ; a, b]=\frac{h(b)-h(a)}{b-a}$, the divided difference.

Coarser, but perhaps more useful bounds are also obtained using Grüss, Chebychev and Lupaş inequalities. Application for the expectation is presented in Section 3.

\section{The Results}

The following result holds.

Received June 14, 2001.

2000 Mathematics Subject Classification. Primary 26D15; Secondary 26D10, 26D99, 41A55.

Key words and phrases. Perturbed trapezoid formula, Sharp bounds. 
Theorem 1. Let $f:[a, b] \rightarrow \mathbb{R}$ be a differentiable function such that $f^{\prime}$ is absolutely continuous on $[a, b]$. If $f^{\prime \prime} \in L_{2}[a, b]$, then

$$
\begin{aligned}
& \left|\int_{a}^{b} f(x) d x-(b-a) \frac{f(a)+f(b)}{2}+\frac{(b-a)^{3}}{12}\left[f^{\prime} ; a, b\right]\right| \\
\leq & \frac{(b-a)^{3}}{12 \sqrt{5}}\left[\frac{1}{b-a}\left\|f^{\prime \prime}\right\|_{2}^{2}-\left[f^{\prime} ; a, b\right]^{2}\right]^{\frac{1}{2}},
\end{aligned}
$$

where $\left[f^{\prime} ; a, b\right]$ is the divided difference $\frac{f^{\prime}(b)-f^{\prime}(a)}{b-a}$.

The constant $\kappa=\frac{1}{12 \sqrt{5}}$ is best possible in the sense that it cannot be replaced by a smaller one.

Proof. Using the integration by parts formula twice, we may state (see for example [2]) that

$$
\int_{a}^{b} f(x) d x-\frac{b-a}{2}[f(a)+f(b)]=-\frac{1}{2} \int_{a}^{b}(x-a)(b-x) f^{\prime \prime}(x) d x .
$$

On the other hand, by Korkine's identity, i.e.,

$$
\begin{aligned}
& \frac{1}{b-a} \int_{a}^{b} h(x) g(x) d x-\frac{1}{b-a} \int_{a}^{b} h(x) d x \cdot \frac{1}{b-a} \int_{a}^{b} g(x) d x \\
= & \frac{1}{2(b-a)^{2}} \int_{a}^{b} \int_{a}^{b}(h(x)-h(y))(g(x)-g(y)) d x d y
\end{aligned}
$$

(which can easily be proved by direct computation), we may state that

$$
\begin{aligned}
& \int_{a}^{b}(x-a)(b-x) f^{\prime \prime}(x) d x-\frac{1}{b-a} \int_{a}^{b}(x-a)(b-x) d x \int_{a}^{b} f^{\prime \prime}(x) d x \\
= & \frac{1}{2(b-a)} \int_{a}^{b} \int_{a}^{b}[(x-a)(b-x)-(y-a)(b-y)]\left[f^{\prime \prime}(x)-f^{\prime \prime}(y)\right] d x d y,
\end{aligned}
$$

which is clearly equivalent to

$$
\begin{aligned}
& \int_{a}^{b}(x-a)(b-x) f^{\prime \prime}(x) d x \\
= & \frac{(b-a)^{2}}{6}\left[f^{\prime}(b)-f^{\prime}(a)\right] \\
& +\frac{1}{2(b-a)} \int_{a}^{b} \int_{a}^{b}[(x-a)(b-x)-(y-a)(b-y)]\left[f^{\prime \prime}(x)-f^{\prime \prime}(y)\right] d x d y .
\end{aligned}
$$

Combining (2.2) with (2.3), we get the identity

$$
\int_{a}^{b} f(x) d x-\frac{b-a}{2}[f(a)+f(b)]+\frac{1}{12}(b-a)^{2}\left[f^{\prime}(b)-f^{\prime}(a)\right]=R[f],
$$


where

$$
R[f]:=-\frac{1}{4(b-a)} \int_{a}^{b} \int_{a}^{b}[(x-a)(b-x)-(y-a)(b-y)]\left[f^{\prime \prime}(x)-f^{\prime \prime}(y)\right] d x d y .
$$

Now, using the Cauchy-Buniakowski-Schwartz inequality for double integrals, we may write:

$$
\begin{aligned}
|R[f]| \leq & \frac{1}{4(b-a)}\left[\int_{a}^{b} \int_{a}^{b}[(x-a)(b-x)-(y-a)(b-y)]^{2} d x d y\right]^{\frac{1}{2}} \\
& \times\left[\int_{a}^{b} \int_{a}^{b}\left[f^{\prime \prime}(x)-f^{\prime \prime}(y)\right]^{2} d x d y\right]^{\frac{1}{2}} \\
= & M .
\end{aligned}
$$

However,

$$
\begin{aligned}
I & :=\int_{a}^{b} \int_{a}^{b}[(x-a)(b-x)-(y-a)(b-y)]^{2} d x d y \\
& =2\left[(b-a) \int_{a}^{b}(x-a)^{2}(b-x)^{2} d x-\left[\int_{a}^{b}(x-a)(b-x) d x\right]^{2}\right] .
\end{aligned}
$$

Using the change of variable $x=(1-t) a+t b, t \in[0,1]$, we get

$$
\begin{aligned}
I & =2\left[(b-a)(b-a)^{5} \int_{0}^{1} t^{2}(1-t)^{2} d t-(b-a)^{6}\left(\int_{0}^{1} t(1-t) d t\right)^{2}\right] \\
& =2(b-a)^{6}\left[\int_{0}^{1}\left(t^{4}-2 t^{3}+t^{2}\right) d t-\left(\int_{0}^{1} t d t-\int_{0}^{1} t^{2} d t\right)^{2}\right] \\
& =\frac{(b-a)^{6}}{2 \cdot 3^{2} \cdot 5} .
\end{aligned}
$$

Also,

$$
\begin{aligned}
\int_{a}^{b} \int_{a}^{b}\left[f^{\prime \prime}(x)-f^{\prime \prime}(y)\right]^{2} d x d y & =2\left[(b-a)\left\|f^{\prime \prime}\right\|_{2}^{2}-(b-a)^{2}\left[f^{\prime} ; a, b\right]^{2}\right] \\
& =2(b-a)^{2}\left[\frac{1}{b-a}\left\|f^{\prime \prime}\right\|_{2}^{2}-\left[f^{\prime} ; a, b\right]^{2}\right] .
\end{aligned}
$$

Then

$$
\begin{aligned}
M & =\frac{1}{4(b-a)} \cdot \frac{(b-a)^{3}}{3 \sqrt{10}} \cdot \sqrt{2}(b-a)\left[\frac{1}{b-a}\left\|f^{\prime \prime}\right\|_{2}^{2}-\left[f^{\prime} ; a, b\right]^{2}\right]^{\frac{1}{2}} \\
& =\frac{(b-a)^{3}}{12 \sqrt{5}}\left[\frac{1}{b-a}\left\|f^{\prime \prime}\right\|_{2}^{2}-\left[f^{\prime} ; a, b\right]^{2}\right]^{\frac{1}{2}} .
\end{aligned}
$$


Using (2.4), we end up with the desired inequality (2.1).

We assume that the inequality (2.2) holds with a constant $\kappa>0$, i.e.,

$$
\begin{aligned}
& \left|\int_{a}^{b} f(x) d x-(b-a) \frac{f(a)+f(b)}{2}+\frac{(b-a)^{3}}{12}\left[f^{\prime} ; a, b\right]\right| \\
\leq & \kappa(b-a)^{3}\left[\frac{1}{b-a}\left\|f^{\prime \prime}\right\|_{2}^{2}-\left[f^{\prime} ; a, b\right]^{2}\right]^{\frac{1}{2}} .
\end{aligned}
$$

Choosing $a=0, b=1$ and $f:[0,1] \rightarrow \mathbb{R}, f(t)=-\frac{1}{2} t^{4}+t^{3}$, we get

$$
\int_{a}^{b} f(t) d t=\frac{3}{20}, \quad(b-a) \frac{f(a)+f(b)}{2}=\frac{1}{4}, \quad \frac{(b-a)^{3}}{12}\left[f^{\prime} ; a, b\right]=\frac{1}{12},
$$

and the left side of (2.5) will be $L_{s}=\frac{3}{20}-\frac{1}{4}+\frac{1}{12}=\frac{1}{60}$. Also,

$$
\frac{1}{b-a}\left\|f^{\prime \prime}\right\|_{2}^{2}=36 \cdot \frac{1}{30}=\frac{6}{5}, \quad\left[f^{\prime} ; a, b\right]^{2}=1
$$

and then

$$
\frac{1}{b-a}\left\|f^{\prime \prime}\right\|_{2}^{2}-\left[f^{\prime} ; a, b\right]^{2}=\frac{6}{5}-1=\frac{1}{5} .
$$

Consequently, the right side of (2.5) is

$$
L_{r}=\kappa \cdot \frac{1}{\sqrt{5}} .
$$

Putting $L_{s}$ and $L_{r}$ in (2.5), we deduce that $\kappa \geq \frac{\sqrt{5}}{60}=\frac{1}{12 \sqrt{5}}$, proving the fact that $\kappa=\frac{1}{12 \sqrt{5}}$ is the best possible in (2.1).

Remark 1. 1. The Grüss integral inequality for a function $g:[a, b] \rightarrow \mathbb{R}$ with $-\infty<m \leq g(x) \leq M<\infty$ for a.e. $x \in[a, b]$ states that (see for example [5, p. 296]):

$$
0 \leq \frac{1}{b-a}\|g\|_{2}^{2}-\left(\frac{1}{b-a} \int_{a}^{b} g\right)^{2} \leq \frac{1}{4}(M-m)^{2} .
$$

Applying (2.6) for the mapping $f^{\prime \prime}$ under the assumption that $\gamma \leq f^{\prime \prime}(x) \leq \Gamma$ for a.e. $x \in[a, b]$, we deduce

$$
\left(\frac{1}{b-a}\left\|f^{\prime \prime}\right\|_{2}^{2}-\left[f^{\prime} ; a, b\right]^{2}\right)^{\frac{1}{2}} \leq \frac{1}{2}(\Gamma-\gamma)
$$

and then, by (2.1) we deduce

$$
\left|\int_{a}^{b} f(x) d x-\frac{b-a}{2}[f(a)+f(b)]+\frac{(b-a)^{3}}{12}\left[f^{\prime} ; a, b\right]\right| \leq \frac{(b-a)^{3}}{24 \sqrt{5}}(\Gamma-\gamma),
$$


which is the result obtained by Cerone and Dragomir in [3].

This shows that (2.1) is a refinement of (2.7).

2. The Chebychev inequality for a differentiable function $g:[a, b] \rightarrow \mathbb{R}$ with $g^{\prime} \in$ $L_{\infty}[a, b]$ states that (see [5, p. 297])

$$
0 \leq \frac{1}{b-a}\|g\|_{2}^{2}-\left(\frac{1}{b-a} \int_{a}^{b} g\right)^{2} \leq \frac{1}{12}(b-a)^{2}\left\|g^{\prime}\right\|_{\infty}^{2} .
$$

Applying (2.8) for the function $f^{\prime \prime}$ under the assumption that $f^{\prime \prime \prime} \in L_{\infty}[a, b]$, we deduce, by (2.1), that

$$
\left|\int_{a}^{b} f(x) d x-\frac{b-a}{2}[f(a)+f(b)]+\frac{(b-a)^{3}}{12}\left[f^{\prime} ; a, b\right]\right| \leq \frac{(b-a)^{4}}{24 \sqrt{15}}\left\|f^{\prime \prime \prime}\right\|_{\infty} .
$$

3. Lupaş' inequality for a differentiable function $f$ with $f^{\prime} \in L_{2}[a, b]$ says that (see $[5$, p. 301])

$$
0 \leq \frac{1}{b-a}\|g\|_{2}^{2}-\left(\frac{1}{b-a} \int_{a}^{b} g\right)^{2} \leq \frac{b-a}{\pi^{2}}\left\|g^{\prime}\right\|_{2}^{2} .
$$

Applying (2.10) for the function $f^{\prime \prime}$ with the assumption that $f^{\prime \prime \prime} \in L_{2}[a, b]$, we deduce, by (2.1), that

$$
\left|\int_{a}^{b} f(x) d x-\frac{b-a}{2}[f(a)+f(b)]+\frac{(b-a)^{3}}{12}\left[f^{\prime} ; a, b\right]\right| \leq \frac{(b-a)^{\frac{7}{2}}\left\|f^{\prime \prime \prime}\right\|_{2}}{12 \pi \sqrt{5}} .
$$

\section{Applications for Expectation}

Let $X$ be a random variable having the p.d.f., $f:[a, b] \rightarrow \mathbb{R}$ and the cumulative distribution function (cdf) $F:[a, b] \rightarrow[0,1]$, that is,

$$
F(x)=\int_{a}^{x} f(t) d t, \quad x \in[a, b] .
$$

The following result holds.

Theorem 2. With the above assumptions and if the p.d.f. is absolutely continuous on $[a, b]$, then we have the inequality:

$$
\begin{aligned}
& \left|E(X)-\frac{a+b}{2}-\frac{(b-a)^{2}}{12}[f(b)-f(a)]\right| \\
\leq & \frac{(b-a)^{3}}{12 \sqrt{5}}\left[\frac{1}{b-a}\left\|f^{\prime}\right\|_{2}^{2}-[f ; a, b]^{2}\right]^{\frac{1}{2}} \\
\leq & \frac{(b-a)^{3}}{24 \sqrt{5}}(\Gamma-\gamma) \text { where } \gamma \leq f^{\prime}(t) \leq \Gamma \text { for } t \in[a, b] .
\end{aligned}
$$


Proof. Applying Theorem 1 for the c.d.f., $F$, we may write that

$$
\begin{aligned}
& \left|\int_{a}^{b} F(t) d t-\frac{F(a)+F(b)}{2}(b-a)+\frac{(b-a)^{2}}{12}[f(b)-f(a)]\right| \\
\leq & \frac{(b-a)^{3}}{12 \sqrt{5}}\left[\frac{1}{b-a}\left\|f^{\prime}\right\|_{2}^{2}-[f ; a, b]^{2}\right]^{\frac{1}{2}} .
\end{aligned}
$$

However, $F(a)=0, F(b)=1$ and

$$
\int_{a}^{b} F(t) d t=b-E(X)
$$

and then, by (3.2) we deduce the first inequality in (3.1).

The second inequality is obtained from (2.6) since

$$
0 \leq\left[\frac{1}{b-a}\left\|f^{\prime}\right\|_{2}^{2}-[f ; a, b]^{2}\right]^{\frac{1}{2}} \leq \frac{\Gamma-\gamma}{2} .
$$

\section{References}

[1] K. E. Atkinson, An Introduction to Numerical Analysis, Wiley and Sons, Second Edition, 1989.

[2] N. S. Barnett and S. S. Dragomir, On the perturbed trapezoid formula, submitted to Soochow J. Math.

[3] P. Cerone and S. S. Dragomir, Trapezoidal type rules from an inequalities point of view, Handbook of Analytic-Computational Methods in Applied Mathematics, G. A. Anastassiou (Ed), CRC Press, New York (2000), 65-134.

[4] S. S. Dragomir, P. Cerone and A. Sofo, Some remarks on the trapezoid rule in numerical integration, Indian J. of Pure and Appl. Math. 31 (2000), 475-494. Preprint: RGMIA Res. Rep. Coll. 2 (1999), No. 5, Article 1. [ONLINE] http://rgmia.vu.edu.au/v2n5.html.

[5] D. S. Mitrinović, J. E. Pečarić and A. M. Fink, Classical and New Inequalities in Analysis, Kluwer Academic Publishers, 1993.

School of Communications and Informatics, Victoria University of Technology, PO Box 14428, Melbourne City MC, Victoria 8001, Australia.

E-mail: neil@matilda.vu.edu.au

http://sci.vu.edu.au/scistaff/index.html

E-mail: pc@matilda.vu.edu.au

http://rgmia.vu.edu.au/cerone

E-mail: sever@matilda.vu.edu.au

http://rgmia.vu.edu.au/SSDragomirWeb.html 